\title{
The Noc proteins involved in ribosome synthesis and export contain divergent HEAT repeats
}

\author{
MENSUR DLAKIĆ ${ }^{1,2}$ and DAVID TOLLERVEY ${ }^{2}$ \\ ${ }^{1}$ Department of Microbiology, Montana State University, Bozeman, Montana 59717-3520, USA \\ ${ }^{2}$ Wellcome Trust Centre for Cell Biology, University of Edinburgh, Edinburgh EH9 3JR, UK
}

\begin{abstract}
The Noc1-4p proteins were previously reported to be involved in intranuclear and nucleocytoplasmic transport of preribosomes. Using fold recognition and structural modeling, we show that Noc1-4p are largely comprised of $\alpha$-helical repeats similar to HEAT repeats. Because other HEAT-repeat proteins play key roles in transport processes, this finding provides a plausible mechanistic explanation for the function of the Noc proteins.
\end{abstract}

Keywords: rRNA; ribosome formation; ribonucleoproteins; molecular models; yeast

Eukaryotic ribosomes are assembled in the nucleolus in a series of highly coordinated events (for review, see Fatica and Tollervey 2002; Tschochner and Hurt 2003). In recent years, several reports have described around 140 nonribosomal factors involved in this multistep process (Harnpicharnchai et al. 2001; Dragon et al. 2002; Fatica et al. 2002; Grandi et al. 2002; Nissan et al. 2002). An important aspect of ribosome subunit synthesis is their transport from the nucleolus to nucleoplasm and then to the cytoplasm. Two recent reports identified a family of pre-ribosome-associated transport factors termed Noc proteins (Milkereit et al. 2001, 2003). These proteins are involved in intranuclear transport and export of the pre-60S subunit (Noc1/2/3p) and nuclear export of the pre-40S subunit (Noc4p). Moreover, Noc3p also plays a key role in the initiation of DNA replication (Zhang et al. 2002). The biochemical and genetic characterization of the Noc proteins (Milkereit et al. 2001, 2003) did not, however, reveal the mechanism(s) by which they mediate ribosomal subunit transport.

Limited sequence similarity between the Noc1/3/4p proteins over a short region of $\sim 45$ residues has been noted previously (Milkereit et al. 2001, 2003). Using profile consistency analysis (Pei et al. 2003), we have extended this alignment into a larger Noc domain (Fig. 1). This extended similarity provides further evidence that these proteins have

Reprint requests to: Mensur Dlakić, Department of Microbiology, Montana State University, Bozeman, MT 59717-3520, USA; e-mail: mdlakic@montana.edu; fax: (406) 994-4926.

Article and publication are at http://www.rnajournal.org/cgi/doi/ 10.1261/rna.5184704. related functions despite their nonredundancy. Orthologs of Noc proteins are present in all higher eukaryotes and were used as starting queries for PSI-BLAST searches (Altschul et al. 1997). We could not identify convincing sequence similarity to proteins of known structure or function. The search of the hidden Markov model (HMM) database of protein families (Bateman et al. 2000) resulted in Noc1p and Noc3p matching CBF/Mak21 domain (PF03914). The annotation for this domain, however, contains no additional information beyond what is already known about Noc proteins. Multiple alignments of Noc proteins were then used to train HMMs and scan the protein database, but again, no informative matches were found. We therefore resorted to fold recognition using the 3D-PSSM server (http://www.sbg.bio.ic.ac.uk/ 3dpssm/; Kelley et al. 2000). With confidence in the range 70\%-90\%, the server returned predictions that all Noc proteins share structural similarity with proteins containing HEAT/Armadillo repeats (Andrade and Bork 1995; Andrade et al. 2001). This prediction was confirmed using the consensus of multiple fold recognition methods at the 3D-Jury metaserver (Ginalski et al. 2003). In a follow-up to this prediction, we compared Noc proteins to HMMs trained on all major classes of HEAT-repeat proteins (Andrade et al. 2001). Noc2p and Noc4p had no sequence similarity to known HEAT repeats with $E<10$, while Noc1p and Noc3p had five and two HEAT repeats, respectively, with statistically insignificant $E$-values ( $E=6.9$ for Noclp and $E=1$ for Noc3p). We conclude that at the sequence level Noc proteins do not have convincing sequence similarity to any of the major classes of HEAT repeats previously described (Andrade et al. 2001). 

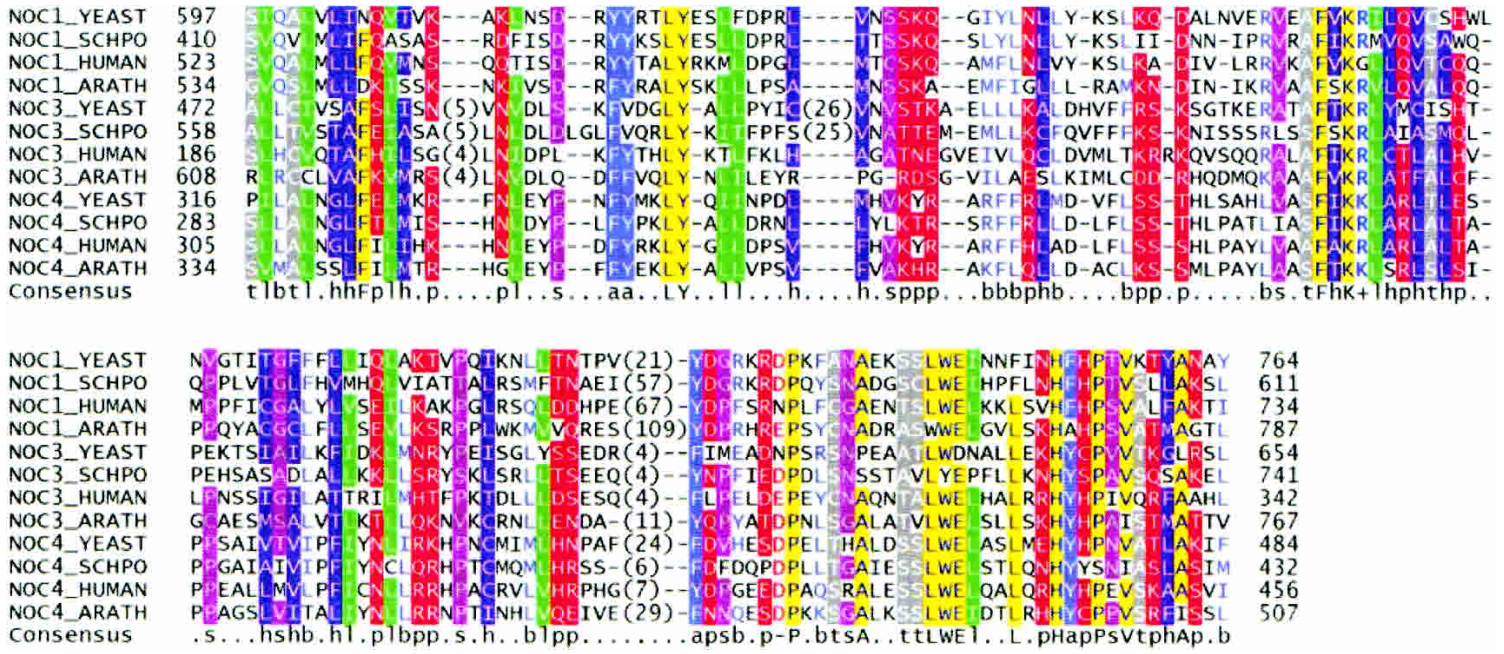

FIGURE 1. Multiple sequence alignment of Noc1/3/4p proteins. Numbers flanking the alignment correspond to parts of proteins that were aligned. Numbers in parentheses indicate lengths of sequences that were omitted due to insertions or deletions. Protein names are separated by an underscore from species abbreviations: YEAST, Saccharomyces cerevisiae; SCHPO, Schizosaccharmyces pombe; HUMAN, Homo sapiens; ARATH, Arabidopsis thaliana. Letters on the consensus line are: $s$, small residues; $t$, tiny; $b$, big; $h$, hydrophobic; $a$, aromatic; $l$, aliphatic; $p$, polar; $c$, charged; - , negatively charged; +, positively charged. Individual residues with more than $80 \%$ identity in the entire alignment are colored yellow and shown as capital letters on the consensus line.

The plausibility of the fold recognition prediction and the degree of structural similarity with known HEAT-repeat proteins were further tested by building 3D models of all Noc proteins (Sali and Blundell 1993). Shown in Figure 2 are models for Noc1p (residues 349-771) and Noc2p (residues 146-699). The models were evaluated using quality

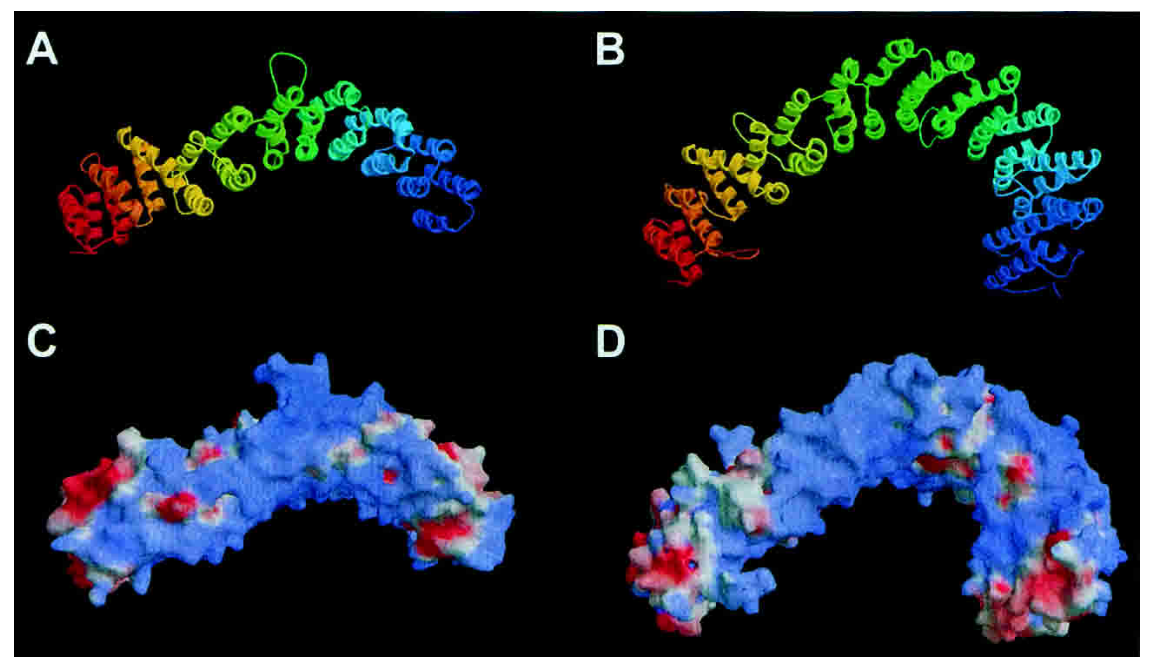

FIGURE 2. $(A, B)$ 3D-models of Noc1p and Noc2p. Noc1p model (residues 349-771) and Noc2p model (residues 146-699) were built with MODELLER (Sali and Blundell 1993) using the PR65/A subunit of protein phosphatase 2A (Groves et al. 1999) as a template. Automatic alignments obtained by 3D-PSSM (Kelley et al. 2000) were corrected manually to minimize insertions and deletions within secondary structure elements of the template. Colors change from blue at the $\mathrm{N}$-terminus to red at the C-terminus. $(C, D)$ Electrostatic potential representations of Noc1p and Noc2p models. Electrostatic surface potential was calculated using GRASP (Nicholls et al. 1991). Blue and red colors correspond to positive and negative potential, respectively. Strong clusters of positive charge suggest that these proteins may interact with other negatively charged molecules, rRNA being an obvious candidate. criteria for comparative modeling (Sanchez and Sali 1998). A probability $(p G)$ that estimates the reliability of the overall fold of protein models was calculated for each Noc protein. Models with $p G>0.7$ are considered to have a correct overall fold (Sanchez and Sali 1998), although they will not be correct in all details. According to these criteria, models of Noc proteins are very reliable $(p G N o c 1 p=0.97 ; p G N o c 2 p=0.96$; $p G N o c 3 p=0.94 ; p G N o c 4 p=0.78)$. This is particularly convincing because the Noc proteins show only $8-13 \%$ identity with the templates used for modeling, and in this range of sequence identity high $p G$ values are unlikely unless the structural relationship between model and the template is genuine. The locations of the predicted HEAT repeat elements in the primary sequence of Noclp are shown in Supplementary Figure S1 (http://www.homepage.montana. edu/ mdlakic/heat_Noc1p_suppl_FIG1. html).

In addition to the Noc proteins, we have identified four other essential HEAT-repeat proteins that are associated with yeast pre-ribosomes: Rrp12p, Sda1p, Utp10p, and Utp20p (Oeffinger et al. 2004). It was recently estimated that at least $0.2 \%$ of eukaryotic proteins have HEAT or Armadillo repeats (Andrade et al. 2001). This abundance may reflect the functional versatility of pro- 
teins with HEAT repeats. The PR65/A subunit of protein phosphatase 2A (PP2A) functions as a scaffold for assembly of the catalytic and regulatory subunits (Groves et al. 1999), while the importin- $\beta /$ karyopherin- $\beta$ (imp- $\beta /$ kap- $\beta$ ) family act as molecular transporters across the nuclear envelope (Gorlich et al. 1997; Malik et al. 1997; Chook and Blobel 1999; Cingolani et al. 1999; Kobe et al. 1999; Vetter et al. 1999). Many assembly and transport steps are critical for ribosome biogenesis, potentially involving multiple HEATrepeat proteins.

Ribosome synthesis dominates nucleocytoplasmic transport in yeast, with each nuclear pore complex (NPC) importing $\sim 1000$ ribosomal proteins and exporting $\sim 25$ ribosomal subunits per minute (for review, see Jorgensen et al. 2004). Efficient import of ribosomal proteins relies on multiple, partially redundant members of the imp- $\beta / \mathrm{kap}-\beta$ family, the founding member of which has a HEAT-repeat structure (Chook and Blobel 1999; Cingolani et al. 1999; Vetter et al. 1999). Ribosome export is also known to require a member of the imp- $\beta / \mathrm{kap}-\beta$ family, Crm1p/Xpolp (for review, see Johnson et al. 2002; Tschochner and Hurt 2003), but it is unlikely that single extrinsic factor mediates the export of the very large ribosomal subunits. We therefore predict that efficient subunit export will require multiple transport factors. At least one of the other HEATrepeat proteins we have identified, Rrp12p, is required for ribosomal subunit export (Oeffinger et al. 2004).

Here we have reported that pre-ribosomes are associated with a family of divergent HEAT-repeat proteins, which are required for ribosomal subunit transport. The Noc proteins are structurally, and potentially functionally, related to general transport factors, despite lacking detectable sequence similarity to known HEAT-repeat proteins. Future studies will determine the relative contributions of these versatile proteins to ribosome assembly and subunit transport.

\section{ACKNOWLEDGMENTS}

M.D. was supported in part by a Special Fellowship from the Leukemia \& Lymphoma Society. D.T. is supported by the Wellcome Trust.

The publication costs of this article were defrayed in part by payment of page charges. This article must therefore be hereby marked "advertisement" in accordance with 18 USC section 1734 solely to indicate this fact.

Received October 1, 2003; accepted December 10, 2003.

\section{REFERENCES}

Altschul, S.F., Madden, T.L., Schaffer, A.A., Zhang, J., Zhang, Z., Miller, W., and Lipman, D.J. 1997. Gapped BLAST and PSIBLAST: A new generation of protein database search programs. Nucleic Acids Res. 25: 3389-3402.

Andrade, M.A. and Bork, P. 1995. HEAT repeats in the Huntington's disease protein. Nat. Genet. 11: 115-116.

Andrade, M.A., Petosa, C., O’Donoghue, S.I., Muller, C.W., and Bork, P. 2001. Comparison of ARM and HEAT protein repeats. J. Mol.
Biol. 309: 1-18.

Bateman, A., Birney, E., Durbin, R., Eddy, S.R., Howe, K.L., and Sonnhammer, E.L. 2000. The Pfam protein families database. Nucleic Acids Res. 28: 263-266.

Chook, Y.M. and Blobel, G. 1999. Structure of the nuclear transport complex karyopherin-32-Ran·GppNHp. Nature 399: 230-237.

Cingolani, G., Petosa, C., Weis, K., and Muller, C.W. 1999. Structure of importin- $\beta$ bound to the IBB domain of importin- $\alpha$. Nature 399: 221-229.

Dragon, F., Gallagher, J.E., Compagnone-Post, P.A., Mitchell, B.M., Porwancher, K.A., Wehner, K.A., Wormsley, S., Settlage, R.E., Shabanowitz, J., Osheim, Y., et al. 2002. A large nucleolar U3 ribonucleoprotein required for $18 \mathrm{~S}$ ribosomal RNA biogenesis. Nature 417: 967-970.

Fatica, A. and Tollervey, D. 2002. Making ribosomes. Curr. Opin. Cell Biol. 14: 313-318.

Fatica, A., Cronshaw, A.D., Dlakic, M., and Tollervey, D. 2002. Ssf1p prevents premature processing of an early pre-60S ribosomal particle. Mol. Cell 9: 341-351.

Ginalski, K., Elofsson, A., Fischer, D., and Rychlewski, L. 2003. 3DJury: A simple approach to improve protein structure predictions. Bioinformatics 19: 1015-1018.

Gorlich, D., Dabrowski, M., Bischoff, F.R., Kutay, U., Bork, P., Hartmann, E., Prehn, S., and Izaurralde, E. 1997. A novel class of RanGTP binding proteins. J. Cell Biol. 138: 65-80.

Grandi, P., Rybin, V., Bassler, J., Petfalski, E., Strauss, D., Marzioch, M., Schafer, T., Kuster, B., Tschochner, H., Tollervey, D., et al. 2002. 90S pre-ribosomes include the 35S pre-rRNA, the U3 snoRNP, and $40 \mathrm{~S}$ subunit processing factors but predominantly lack 60S synthesis factors. Mol. Cell 10: 105-115.

Groves, M.R., Hanlon, N., Turowski, P., Hemmings, B.A., and Barford, D. 1999. The structure of the protein phosphatase 2A PR65/A subunit reveals the conformation of its 15 tandemly repeated HEAT motifs. Cell 96: 99-110.

Harnpicharnchai, P., Jakovljevic, J., Horsey, E., Miles, T., Roman, J., Rout, M., Meagher, D., Imai, B., Guo, Y., Brame, C.J., et al. 2001. Composition and functional characterization of yeast $66 \mathrm{~S}$ ribosome assembly intermediates. Mol. Cell 8: 505-515.

Johnson, A.W., Lund, E., and Dahlberg, J. 2002. Nuclear export of ribosomal subunits. Trends Biochem. Sci. 27: 580-585.

Jorgensen, P., Tyers, M., and Warner, J.R. 2004. Forging the factory: Ribosome synthesis and growth control in budding yeast. In: Cell growth: control of cell size (eds. M.N. Hall et al.). Cold Spring Harbor Laboratory Press, Cold Spring Harbor, NY (in press).

Kelley, L.A., MacCallum, R.M., and Sternberg, M.J. 2000. Enhanced genome annotation using structural profiles in the program $3 \mathrm{D}$ PSSM. J. Mol. Biol. 299: 499-520.

Kobe, B., Gleichmann, T., Horne, J., Jennings, I.G., Scotney, P.D., and Teh, T. 1999. Turn up the HEAT. Structure 7: R91-R97.

Malik, H.S., Eickbush, T.H., and Goldfarb, D.S. 1997. Evolutionary specialization of the nuclear targeting apparatus. Proc. Natl. Acad. Sci. 94: 13738-13742.

Milkereit, P., Gadal, O., Podtelejnikov, A., Trumtel, S., Gas, N., Petfalski, E., Tollervey, D., Mann, M., Hurt, E., and Tschochner, H. 2001. Maturation and intranuclear transport of pre-ribosomes requires Noc proteins. Cell 105: 499-509.

Milkereit, P., Strauss, D., Bassler, J., Gadal, O., Kuhn, H., Schutz, S., Gas, N., Lechner, J., Hurt, E., and Tschochner, H. 2003. A Noc complex specifically involved in the formation and nuclear export of ribosomal $40 \mathrm{~S}$ subunits. J. Biol. Chem. 278: 4072-4081.

Nicholls, A., Sharp, K.A., and Honig, B. 1991. Protein folding and association: Insights from the interfacial and thermodynamic properties of hydrocarbons. Proteins 11: 281-296.

Nissan, T.A., Bassler, J., Petfalski, E., Tollervey, D., and Hurt, E. 2002. $60 \mathrm{~S}$ pre-ribosome formation viewed from assembly in the nucleolus until export to the cytoplasm. EMBO J. 21: 5539-5547.

Oeffinger, M., Dlakic, M., and Tollervey, D. 2004. A pre-ribosome associated HEAT-repeat protein is required for export of both ribosomal subunits. Genes \& Dev. 18: 196-209. 
Pei, J., Sadreyev, R., and Grishin, N.V. 2003. PCMA: Fast and accurate multiple sequence alignment based on profile consistency. Bioinformatics 19: 427-428.

Sali, A. and Blundell, T.L. 1993. Comparative protein modelling by satisfaction of spatial restraints. J. Mol. Biol. 234: 779-815.

Sanchez, R. and Sali, A. 1998. Large-scale protein structure modeling of the Saccharomyces cerevisiae genome. Proc. Natl Acad. Sci. 95: 13597-13602.
Tschochner, H. and Hurt, E. 2003. Pre-ribosomes on the road from the nucleolus to the cytoplasm. Trends Cell Biol. 13: 255-263.

Vetter, I.R., Arndt, A., Kutay, U., Gorlich, D., and Wittinghofer, A. 1999. Structural view of the Ran-Importin $\beta$ interaction at $2.3 \AA$ resolution. Cell 97: 635-646.

Zhang, Y., Yu, Z., Fu, X., and Liang, C. 2002. Noc3p, a bHLH protein, plays an integral role in the initiation of DNA replication in budding yeast. Cell 109: 849-860. 

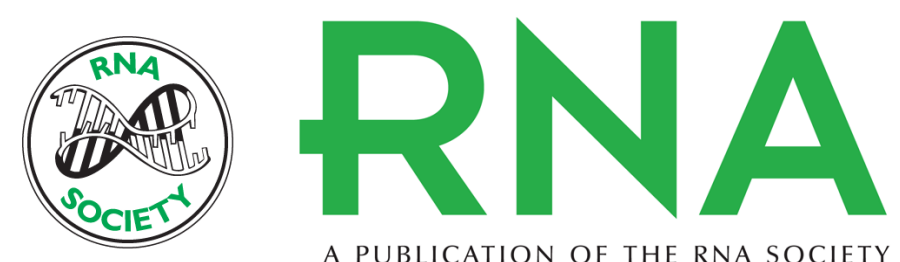

A PUBLICATION OF THE RNA SOCIETY

\section{The Noc proteins involved in ribosome synthesis and export contain divergent HEAT repeats}

MENSUR DLAKIC and DAVID TOLLERVEY

RNA 2004 10: 351-354

References This article cites 29 articles, 6 of which can be accessed free at: http://rnajournal.cshlp.org/content/10/3/351.full.html\#ref-list-1

\section{License}

Email Alerting Receive free email alerts when new articles cite this article - sign up in the box at the Service top right corner of the article or click here. 